\title{
Pilot projects lay foundation for national tissue surveillance and traceability system
}

Published at www.cmaj.ca on Mar. 3

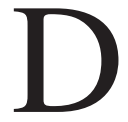
octors in Nova Scotia, Quebec and Alberta are laying the groundwork for a national system to trace tissue from donors to recipients and track adverse reactions related to tissue and organ transplantation.

Once launched, the national tissue and organ surveillance system (TOSS) will be primarily focused on three types of adverse and severe reactions: transmission of infectious diseases, malignancy transfer and graft failure. Ultimately, it's hoped the system, like others being developed internationally, will collect data on moderate and severe adverse events - eventually expanding to include serious errors and near misses - to monitor trends in known and emerging risks (CMAJ 2010. DOI:10.1503/cmaj.109-3196)

The pilot projects were to be completed Mar. 31 in the three provinces as the first phase of a Public Health Agency of Canada (PHAC) bid to create a national surveillance and traceability system within five years. Nationally, over 90000 tissue allografts are distributed for transplantation annually, with approximately $80 \%$ of those imported from the United States.

Cindy Hyson, manager of PHAC's transfusion transplantation adverse events section, says the trio of two-year pilot projects should serve as the foundation for the development of a "chain of reporting" system for adverse events during every facet of a tissue transplant.

"The next step will be to look at what's most feasible, whether it's a sentinel system or whether it's a national system in each and every province," Hyson says.

Hyson says each of the pilot sites focus on a different aspect of data collection. "One site is focusing on an actual survey of end users - physicians, dentists, hospitals, tissue banks

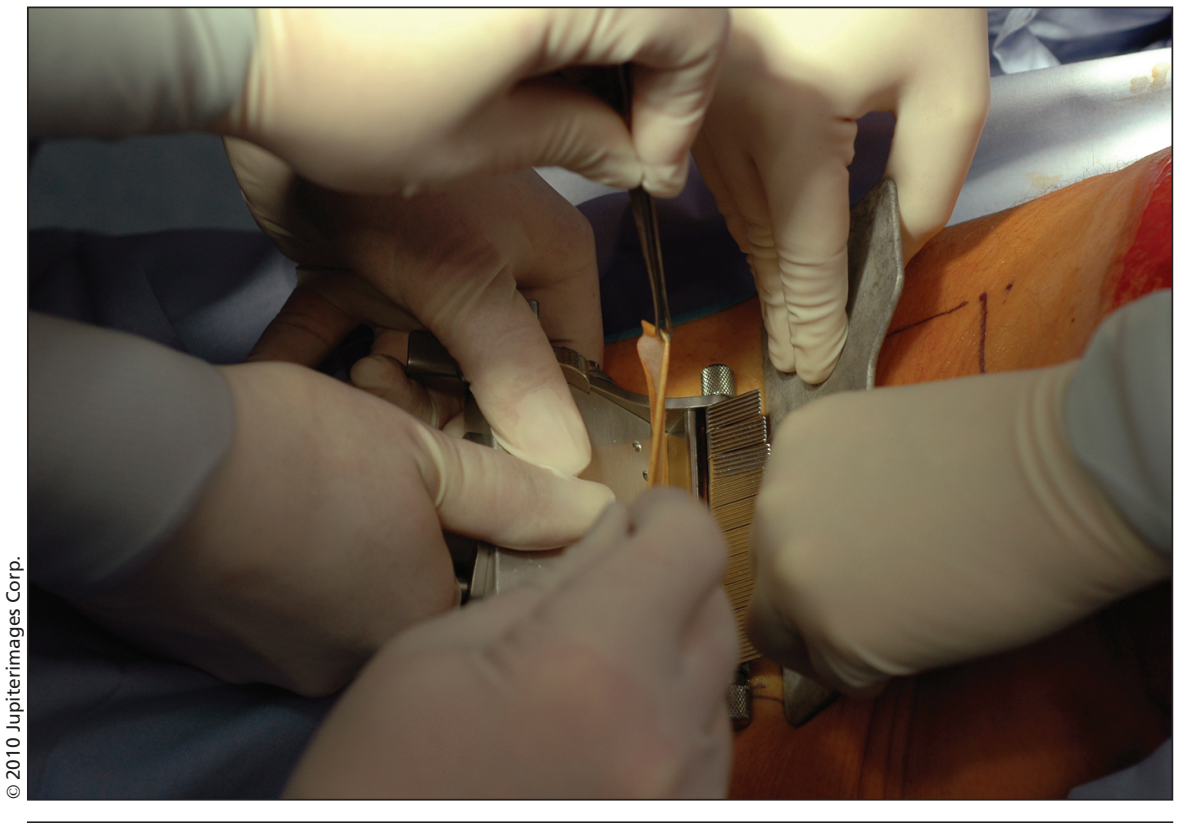

Skin grafts are among the most common forms of tissue transplantation.

- to get some idea as to what's the lay of the land, if you will, for adverse event reporting for transplantation."

"Another site is doing a retrospective chart review in relation to musculoskeletal tissue implants and also ocular tissue implants, to see were there any adverse event transplantation events reported or were there any missed, that when they went back to look, they felt were an adverse transplantation event or maybe they felt were related to the transportation itself."

Hyson adds that the "third pilot site is looking at a combination of the two but also to look at where adverse event reporting happens. Does it happen at the surgeon's office? Does it happen six months later at the family physician? Or does it happen initially in the clinic? It's trying to focus on the disjointedness of the system that exists currently in relation to, if a patient goes from one province to another to be transplanted, and they stay in that province, let's say for three months, and then they're okay to go, then they go back. Do they go back to the nephrologist where they started out? Do they go back to their actual family doctor?"

"We're trying to figure out, in the chain of command, who is reporting and what they are actually reporting."

Hyson adds that organizers also hope to get a better sense of how many adverse events are being reported and what's the precise nature of those events. "Is it a transmission of an infection that's not been picked up" or malignant tumours, or some other adverse event?

Nova Scotia's blood coordinating program was selected as one of the pilots in part because of its past success with the Transfusion Transmitted Injuries Surveillance System, which tracks blood transfusions and might serve as a model for a tissue surveillance system.

In a bid to assess the current landscape of transplant activities, patient notification and adverse transplantation reaction reporting within the province, 
the project team has completed a physician survey and launched an environmental scan.

The survey provided an opportunity for physicians who perform tissue transplants, or provide care to patients following such procedures, to participate in the development of the surveillance system, says Cynthia Johnston, project coordinator with the Nova Scotia Provincial Blood Coordinating Program.

"We're trying to determine what data needs to be collected" and then collect it from physicians, says Johnston, a member of the national data working group, one of two committees established by PHAC in partnership with the Canadian Council for Donation and Transplantation, to oversee the national initiative.

Significant issues have already been identified, including "just how many products are actually used and by whom," Johnston adds.

At a 2007 workshop to discuss options for surveillance and traceability in tissue transplantation in Canada, participants were informed that planners took it as a "given" that there were a number of assumed obstacles to the creation of a national system, according to a report, Enhancing Tissue Banking in Canada, Phase II: Surveillance and Traceability in Tissue Transplantation (http://dsp-psd.pwgsc.gc.ca/collection _2008/hc-sc/H14-13-2-2007E.pdf).

Those assumptions were:

- "Health privacy legislation is perceived as a barrier to the exchange of recipient information between end users and tissue banks.

- "The utilization of information technology within Canadian tissue surveillance and traceability is limited and uncoordinated.

- "Participation of end users in the provision of recipient information to tissue banks varies significantly.

- "Tissue bank practices in requesting recipient information from end users vary significantly.

- "There is a lack of identification and under-reporting of potential adverse events.

- "A lack of common terminology, education and guidelines in relation to adverse-event surveillance is a barrier to the identification and reporting of events.

- "Identification and reporting of adverse events varies among enduser groups."

Presented with six options featuring varying degrees of centralization, workshop participants recommended the creation of a centralized national system. "Such a system would improve patient safety and create an important link between donation/transplantation and surveillance/traceability - thereby increasing safety, transparency and confidence," states the report on the proceedings. "Although linking the tissue system with the existing blood system would be financially effective, it was felt that end users might respond negatively to a system that is further removed from national organ and tissue governance. A centralized system, including a national register, is essential to tracking both material transferred across Canada and the large volume of tissue imported from outside the country. It would also be useful in situations were global rapid alert is important."

Johnston says organizers are optimistic that a national system can be developed within five years. - donalee Moulton, Halifax, NS, and Wayne Kondro, CMAJ

DOI:10.1503/cmaj.109-3195

Second of a series on national tissue surveillance

Part 1: Globa shift towards increased biovigilance (CMAJ 2010. DOI:10.1503/cmaj.109-3196) 